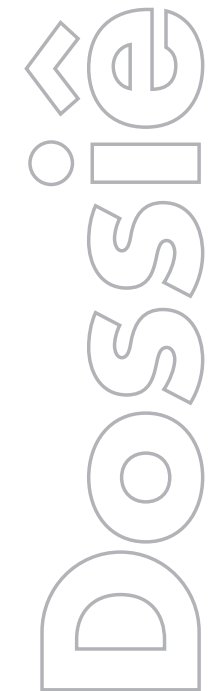

\section{revista}

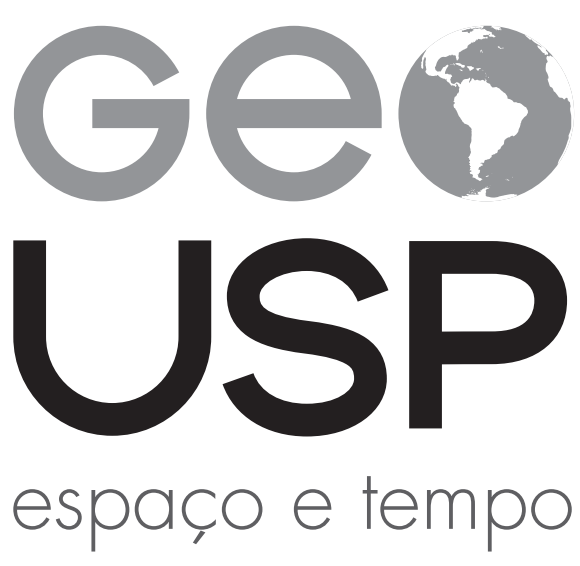

Volume $22 \cdot n^{\circ} 3$ (2018)

\title{
Geografia agrária crítica: um pouco de história
}

Marta Inez Medeiros Marques

USP

p. $504-514$

Como citar este artigo:

MARQUES, M. I. M. Geografia agrária crítica: um pouco de história. Geousp - Espaço e Tempo (Online), v. 22, n. 3, p. 504-514, dez. 2018. ISSN 2179-0892.

Disponível em: <https://www.revistas.usp.br/geousp/article/view/153292 >. doi: http://dx.doi.org/10.11606/issn.21790892.geousp.2018.153292.

\section{(c) $(1)(9$}

Este artigo está licenciado sob a Creative Commons Attribution 4.0 License. 


\title{
Geografia agrária crítica: um pouco de história
}

\section{Resumo}

Este artigo analisa o contexto histórico e o teor do debate acadêmico na origem da virada radical da geografia brasileira e trata do surgimento e da trajetória da geografia agrária desenvolvida a partir da perspectiva crítica, tendo como referência a escola de pensamento criada na Universidade de São Paulo (USP) sob a liderança intelectual de Ariovaldo Umbelino de Oliveira. $O$ texto se baseia no levantamento bibliográfico e em registros pessoais da autora e reproduz, em linhas gerais, a apresentação feita no Seminário 40 anos de Geografia Crítica".

Palavras-chave: Geografia crítica. Geografia agrária. Ariovaldo U. de Oliveira. Questão agrária. Desenvolvimento desigual e combinado do capitalismo.

\section{Critical Agrarian Geography: a little history}

\begin{abstract}
This article analyzes the historical context and the content of the academic debate that are at the origin of the radical turn of Brazilian geography and focus on the emergence and trajectory of the agrarian geography developed from the critical perspective, taking as reference the School of thought created at the University of São Paulo (USP) under the intellectual leadership of Ariovaldo Umbelino de Oliveira. The article is based on bibliographical research and personal records of the author and reproduces in general lines the presentation held in the seminar "40 years of Critical Geography".
\end{abstract}

Keywords: Critical geography. Agrarian Geography. Ariovaldo U. de Oliveira. Agrarian question. Uneven and combined development of capitalism.

\section{Introdução}

Em 2018, a geografia crítica completou 40 anos e temos boas razões para comemorar o resultado de sua trajetória, uma obra que vem sendo elaborada coletivamente e na qual muitos de nós tomamos parte. Apesar dos desafios e das dificuldades enfrentados ao longo de sua história, se mantém vivo e operante o projeto de construção de um pensamento capaz 
de apreender o movimento da realidade em suas contradições, a fim de superá-las, a partir da perspectiva geográfica.

Nesse sentido, a realização de um seminário para celebrar esse aniversário é um ato político, além de acadêmico. Ele se justifica pelo entendimento de que é preciso cultivar a memória, pois, se não sabemos de onde viemos, não saberemos para onde vamos.

Este artigo parte da apresentação de aspectos do contexto histórico e do debate acadêmico que estão na origem da virada radical da geografia brasileira e analisa o surgimento e a trajetória da geografia agrária desenvolvida a partir da perspectiva crítica, tomando como referência a escola de pensamento criada na Universidade de São Paulo (USP) sob a liderança intelectual de Ariovaldo Umbelino de Oliveira.

texto está dividido em três partes, além da introdução e das conclusões finais: (1) contextualização, (2) elementos para uma história do pensamento crítico no campo da geografia agrária e o protagonismo da escola uspiana e (3) desenvolvimento desigual do capitalismo: o campo e a questão agrária ontem e hoje.

\section{Contextualização}

No fim dos anos 1970, o Brasil iniciava um movimento em direção à retomada da democracia após um período de 20 anos sob um regime autoritário, e a geografia se fez presente, atuante, comprometida com o projeto de construção de uma sociedade mais justa. Esse compromisso foi a base a partir da qual a geografia brasileira se renovou, cresceu e ganhou estatura, produzindo um conhecimento crítico, capaz de contribuir para o enfrentamento dos dilemas de seu tempo.

Essa mudança veio junto com uma ruptura epistemológica com a tradição positivista e a difusão do materialismo dialético entre os geógrafos e com o seu reconhecimento como instrumento eficaz para compreender nossos problemas, as suas raízes, os principais sujeitos sociais envolvidos e contribuir para identificar soluções ou delimitar o campo de possibilidades existente para o seu enfrentamento. Nesse processo, a perspectiva dialética se encontrou com velhas e novas abordagens presentes na geografia, que, como não podia deixar ser, também vão provocar as suas marcas no conhecimento que se desenvolveu a partir daí.

Foi elaborada uma crítica à tecnocracia e ao atrelamento a ela realizado pela geografia quantitativista, que se contentava em se restringir à expressão numérica dos fenômenos, detendo-se com frequência na superfície dos fatos. Também se buscou superar o caráter marcadamente descritivo e historicista que caracterizou trabalhos que hoje classificamos como de uma "geografia tradicional".

Vale ressaltar a necessidade de se reconhecer as qualidades de uma boa descrição ou da análise estatística e não se confundir a crítica que foi feita a formas de abordagem reducionistas com uma desqualificação desses procedimentos analíticos e de exposição por si mesmos.

A geografia crítica empreendeu um esforço no sentido de superar o espírito positivo dominante, que se contentava em constatar os fatos. Assim o fez por entender que é preciso ir além deles, buscando apreender relações, formas e configuração sociais em que se inserem e que thes conferem concretude e sentido. Do contrário, como advertiu Lefebvre (1980), cai-se no "fetichismo do real". 
Oano de 1978 foi um marco nesse processo por dois fatos que merecem destaque: (1) lançamento de Por uma geografia nova, de Milton Santos, que representou um consistente ponto de partida para o desenvolvimento do diálogo entre geografia e marxismo no Brasil, e (2) o $3 \circ$ Encontro Nacional de Geógrafos, realizado pela Associação dos Geógrafos do Brasil (AGB) em Fortaleza, onde a prática acadêmica e institucional da geografia foi duramente criticada por seu caráter hierárquico e atrelamento ao poder constituído. A comunicação apresentada no Encontro por Carlos Walter Porto-Gonçalves, denominada "A geografia está em crise. Viva a geografia!", é reveladora do espírito que dominou o evento.

A partir de então, a geografia passa por um processo de renovação e assume um papel protagonista no debate político e a AGB, por um processo de democratização, abrindo-se para uma maior participação dos estudantes na vida da associação.

As reuniões acadêmicas são importantes oportunidades para o encontro e o debate de ideias e guardam estreita sintonia com os processos que marcam a história das diferentes áreas de conhecimento. Assim, vale lembrar que em 1978 é também realizado o primeiro Encontro Nacional de Geografia Agrária (Enga), evento que de início abrigou um segmento significativo de geógrafos que haviam perdido espaço nos encontros da AGB após a sua reestruturação, sendo identificado como reduto da "geografia tradicional", apesar de contar com a participação assídua de representantes da geografia crítica desde suas primeiras edições.

Nesse contexto, a Universidade de São Paulo assumiu um papel central no processo de renovação do pensamento geográfico a partir da liderança de um grupo de estudantes de pós-graduação e com base no apoio que estes encontraram entre professores como Léa Goldenstein, Pasquale Petrone e Manoel Seabra para desenvolver seus trabalhos numa perspectiva crítica. Esses estudantes viriam a se tornar professores dessa instituição a partir dos anos 1980, entre eles, destacam-se: Antonio Carlos Robert de Moraes, Wanderley Messias, André Roberto Martin, Sandra Lencioni, Ana Fani A. Carlos, Amélia Luisa Damiani e Ariovaldo U. de Oliveira.

\section{Elementos para uma história do pensamento crítico no campo da geogra- fia agrária e o protagonismo da escola uspiana}

A geografia agrária é um importante campo do pensamento geográfico brasileiro, marcado pela contribuição de pesquisadores que atuaram nas diferentes regiões do país.

Quando a geografia crítica toma a cena, a geografia agrária se ocupava sobretudo do estudo: (1) da distribuição espacial da produção agrícola e do sentido e da racionalidade em que ela se baseia, (2) do uso da terra e dos sistemas agrícolas, do ponto de vista das técnicas, dos itinerários empregados e de sua relação com o calendário agrícola e a paisagem rural, e (3) das comunidades rurais em sua tradição, particularidades regionais, evolução histórica e dinâmica contemporânea. Esses trabalhos se baseavam na história econômica e em estudos da paisagem de origem alemã e/ou na tradição francesa de estudos regionais, entre outras influências.

Manoel Correia de Andrade e Orlando Valverde já eram autores de destaque no período, tendo alcançado o reconhecimento entre os pares pela excelência de suas pesquisas, apesar de assumirem posições políticas de esquerda. Eles estavam na vanguarda de seu tempo e foram precursores do pensamento crítico no campo da geografia agrária no Brasil. 
Em sua atuação na universidade e também quando de sua passagem pela administração pública durante o governo Arraes em Pernambuco, Manoel Correia esteve envolvido com as lutas sociais no campo e com a causa da reforma agrária. Seu livro A terra e o homem no Nordeste, lançado em 1963 e hoje na oitava edição, foi produzido em diálogo com a obra $A$ formação do Brasil contemporâneo, de Caio Prado Jr., e constitui um marco no pensamento social brasileiro.

Orlando Valverde atuou como pesquisador no IBGE, contribuindo para a formação de uma geração de geógrafos comprometida com as grandes questões nacionais, entre elas, destacam-se a questão agrária e a defesa do meio ambiente na Amazônia. Estudou os sistemas agrícolas existentes em várias regiões do país numa perspectiva empírico-indutiva, sempre mobilizado pela busca de soluções para os problemas sociais e econômicos (Valverde, 1984), tendo como importantes influências o geógrafo alemão Leo Waibel, de um lado, e o Partido Comunista Brasileiro, do outro. Assim como Manoel Correia, ele também defendeu a reforma agrária.

No contexto da geografia crítica, destacam-se nomes da geografia agrária uspiana como Iraci Gomes de V. Palheta, Maria Regina Cunha de Toledo Sader e Ariovaldo U de Oliveira. De formas diferentes, eles contribuíram por meio de seus trabalhos e da formação de pesquisadores para a elaboração de uma nova geografia agrária baseada sobretudo na incorporação do materialismo dialético e da teoria do campesinato originária de estudos da sociologia e da antropologia.

Iraci Gomes Palheta defendeu a sua tese de doutorado O uso da terra em Tauá-Vigia, estado do Pará em 1978, sob a orientação de Antônio Rocha Penteado, na qual desenvolveu uma rica descrição sobre a área de influência imediata de Belém. É no desenrolar de sua carreira como pesquisadora e professora que ela passa a adotar a abordagem da geografia crítica, tendo se dedicado ao estudo da temática da questão agrária na Amazônia, da população e do campesinato, estabelecendo um debate com autores que se ocuparam da análise do campo brasileiro sob a perspectiva do desenvolvimento desigual do capitalismo.

Maria Regina Cunha de Toledo Sader defendeu a tese Espaço e luta no Bico do Papagaio, em 1987, sob orientação de Léa Goldenstein e, com veia mais etnográfica, se ocupou do estudo do campesinato e da questão agrária em situação de fronteira, da migração, dos conflitos sociais e do imaginário camponês sertanejo. $\bigcirc$ seu doutorado foi defendido mais tardiamente, após o seu retorno de um período de exílio na França com o objetivo de se proteger de problemas políticos decorrentes da ditadura militar.

Ariovaldo Umbelino de Oliveira é peça-chave na construção de uma geografia agrária marxista e comprometida com as lutas sociais no campo. Em sua tese de doutorado, Contribuição para o estudo da geografia agrária: crítica ao "estado isolado" de Von Thünen, defendida em 1979 sob a orientação de Pasquale Petrone, ele busca apreender o modo capitalista de pensar a partir de uma abordagem apoiada no materialismo dialético. Sua livre docência, A Amazônia norte mato-grossense: grilagem, corrupção e violência, defendida em 1997, apresenta uma análise das contradições e lutas que marcam a expansão do capitalismo no campo e o consequente aprofundamento da questão agrária. 
Oliveira desenvolveu uma teoria, amplamente aceita e difundida na geografia brasileira, para tratar do desenvolvimento desigual e combinado do capitalismo na agricultura e das formas como o capital monopolista se expande no campo. Ele tratou de temas como: Amazônia, subordinação e reprodução camponesa sob o capitalismo, renda da terra, lutas no campo, reforma agrária, construção do território capitalista, mundialização da agricultura brasileira etc. É autor de uma extensa obra e orientou uma centena de trabalhos de pós-graduação, desempenhando assim um papel central na formação de mais de uma geração de geógrafos.

Em 1998, o Laboratório de Geografia Agrária da Universidade de São Paulo organizou - 1 - Simpósio Nacional de Geografia Agrária como um evento para tratar sobre a questão agrária e as lutas no campo, inovando ao reunir representantes da academia e dos movimentos sociais num debate horizontal. Essa experiência se consolidou com a realização de um novo Simpósio na USP em 2003, com caráter Internacional, dando origem ao Simpósio Nacional e Internacional de Geografia Agrária (Singa), que hoje é reconhecido entre acadêmicos e ativistas na América Latina, para além da área da geografia.

Desde 2004, a revista Agrária ([s.d.]), do Laboratório de Geografia Agrária da USP, tem sido um importante veículo de divulgação e promoção do debate na perspectiva crítica de temas relativos ao campo no Brasil. As revistas Campo-Território (CT, [s.d.]) e Nera ([s.d.])1 têm papel semelhante, evidenciando a potência da abordagem da geografia agrária crítica hoje no país.

A hegemonia do pensamento radical na geografia agrária, seja ele de base marxista ou não, também pode ser observado pela crescente abertura do Enga a partir dos anos 2000 para temas e abordagens da geografia agrária crítica de modo que atualmente há pouca diferença entre esse evento e o Singa.

Nos últimos anos, destaca-se a influência crescente no pensamento geográfico da abordagem decolonial, de grande expressão entre os cientistas sociais latino-americanos que têm atuação militante junto aos sujeitos sociais em luta, sejam camponeses, indígenas ou povos tradicionais. Nessa abordagem, são temas frequentes: a crítica ao eurocentrismo, ao epistemicídio promovido pelo projeto moderno-colonial, à monocultura do saber e à questão ambiental. Além disso, nela também tem se observado a preocupação com questões étnicas e de gênero, contribuindo para dar visibilidade a lutas importantes que a abordagem de classe tem deixado de fora. Carlos Walter Porto-Gonçalves se destaca como um importante representante dessa perspectiva teórica. ${ }^{2}$

Dada a ênfase na diferença e no particular e o desejo de subverter as hierarquias, a abordagem decolonial pode cair na armadilha do voluntarismo e numa apreensão cindida do sistema-mundo, incapaz de abarcar a sua unificação contraditória, produzida e imposta a ferro e fogo pelo capital. Diante disso, Anibal Quijano, conhecido autor decolonial, adverte para a pertinência de se trabalhar com uma noção de totalidade como resultante da imposição de um eixo de articulação ou fator de determinação comum estruturante para experiências histórico-sociais diversas (Quijano, 2010). Essa situação nos lembra da necessidade de enfrentarmos o desafio da contínua reflexão crítica também no interior e entre as diferentes vertentes da própria geografia crítica.

1 Cujos primeiros números não estão datados.

2 Ver, por exemplo, A globalização da natureza e a natureza da globalização. 


\section{Desenvolvimento desigual do capitalismo: o campo e a questão agrária ontem e hoje}

A seguir serão apresentadas as características mais gerais da nova geografia agrária desenvolvida na USP, estruturada a partir de um esforço para compreender os fundamentos dos principais dilemas que caracterizam o campo brasileiro - com destaque para a questão agrária - e na busca de caminhos para superá-los. Considerando-se a amplitude dessa abordagem e o grande número de trabalhos representativos de seus diversos desdobramentos temáticos, optou-se por analisar a contribuição de Oliveira, dada a sua relevância para essa escola de pensamento. Antes, porém, serão apresentados elementos do contexto histórico e do momento em que se encontrava o debate acadêmico quando são desenvolvidas as primeiras formulações dessa escola.

No fim dos anos 1950 e início dos 60, a questão agrária emergiu como um problema central para o país, que demandava solução urgente. Eclodiram conflitos em várias áreas no campo e o movimento dos trabalhadores rurais passou a se organizar em defesa dos direitos trabalhistas e da reforma agrária via sindicato e Ligas Camponesas. Apresentando-se mais combativo nas regiões Nordeste, Sul e Sudeste.

A questão agrária era concebida no debate político e acadêmico sobretudo como um entrave para o desenvolvimento social e econômico do país, que devia se dar por meio da industrialização e a consequente mudança de nossa estrutura social. $\bigcirc$ latifúndio (resquício de relações feudais para alguns) ${ }^{3}$ era então tratado como sinônimo do atraso em termos econômicos e políticos, por limitar o crescimento da produção, dada sua defasagem técnica, impedir o surgimento de uma classe média rural (potencial consumidora dos produtos da indústria) e perpetuar relações de poder estruturadas em torno da propriedade da terra e de diferentes formas de extração da renda da terra.

Porém, a ditadura militar instaurada em 1964 reprimiu fortemente os movimentos sociais e impôs um projeto de modernização conservadora para a agricultura como solução para a integração do setor ao seu projeto de desenvolvimento econômico. Houve uma mudança da base técnica e a crescente vinculação da agricultura à indústria, bem como o seu atrelamento ao setor financeiro, sob o comando do capital monopolista. Esse fato ocorreu simultaneamente à expansão da fronteira agrícola sobre os cerrados e a floresta amazônica, sobre terras de posseiros e de indígenas, com o consequente crescimento de conflitos no campo.

No entanto, verifica-se a permanência de relações de produção não capitalistas, como a produção camponesa e as relações de parceria, entre outras, revelando a complexidade da formação social brasileira, constituída a partir do desenvolvimento desigual e combinado do capitalismo, com a continuada abertura de fronteiras e a atualização de mecanismos da acumulação primitiva. Esses aspectos foram inicialmente analisados por Francisco de Oliveira (1988) no ensaio A economia brasileira: crítica à razão dualista, publicado pela primeira vez em 1972.

No 2॰ Enga, realizado em 1979, José de Sousa Martins apresenta o trabalho "A sujeição da renda da terra ao capital e o novo sentido da luta pela reforma agrária", no qual explica porque a propriedade da terra não constitui um obstáculo para o desenvolvimento do capitalis-

3 Ideia defendida por autores como Nelson Werneck Sodré, Alberto Passos Guimarães, Inácio Rangel e, na geografia, Orlando Valverde (Oliveira, A., 1999, p. 70). 
mo no campo, apesar de representar uma irracionalidade para o capital nos termos da análise marxista. ${ }^{4}$ Assim, para esse autor, a luta pela reforma agrária é também uma luta contra o desenvolvimento do capitalismo no campo.

$\bigcirc$ que vemos claramente tanto no caso da grande propriedade quanto no caso da pequena, é que fundamentalmente o capital tende a se apropriar da renda da terra. $\bigcirc$ capital tem se apropriado diretamente de grandes propriedades ou promovido a sua formação em setores econômicos do campo em que a renda da terra é alta, como no caso da cana, da soja, da pecuária de corte. Onde a renda é baixa, como no caso dos setores de alimentos de consumo interno generalizado [...], o capital não se torna proprietário de terra, mas cria as condições para extrair o excedente econômico, ou seja, especificamente renda onde ela aparentemente não existe (Martins, 1981, p. 175).

Oliveira (1981) acompanha o argumento de Martins e, no artigo "Agricultura e indústria no Brasil", apresentado no 30 Enga, em 1980, analisa como se dá a expansão do capital monopolista no campo a partir do exame da relação entre esses setores da economia. $\bigcirc$ autor entende o desenvolvimento do modo capitalista de produção como desigual e combinado e supõe a criação e recriação continuada de formas sociais não capitalistas. Ele identifica duas situações distintas:

(1) o monopólio na produção, quando a circulação está subordinada à produção como no caso da agroindústria e "a mercadoria sai da produção com o preço de venda ao consumidor estipulado" (Oliveira, 1981, p. 20).

(2) o monopólio na circulação, quando a produção está subordinada à circulação, o que ocorre quando o capital monopolista comercial ou industrial subordina "grandes e pequenos agricultores" por meio de mecanismos quase compulsórios de comercialização das safras, e também os consumidores, com a imposição de preços de monopólio.

Segundo Oliveira, o monopólio na circulação assegura a transferência de excedentes da produção agrícola para o capital monopolista, ou seja, a sujeição da renda da terra. E conclui:

que assistimos é a ação do capital em todas as direções, onde ele não pode extrair juntos lucro e renda, ele assegura o direito de extrair a renda. Dessa forma, a expansão do modo capitalista de produção no campo se dá primeiro e fundamentalmente pela sujeição da renda da terra ao capital. Especulando com a terra, ou subordinando a produção do tipo camponês, o capital dá o primeiro passo (condição necessária para a sujeição da renda da terra) para em seguida sujeitar o trabalho que se dá na terra (Oliveira, 1981, p. 58).

Diferentemente de outros autores da geografia crítica, a análise de Oliveira não privilegia a produção do espaço, mas a construção do território:

4 Marx (1988, p. 220) considera que a propriedade da terra representa uma irracionalidade do ponto de vista do processo de acumulação do capital, na medida em que essa aquisição requer do capitalista a imobilização de parcela de seu capital, reduzindo o investimento direto na produção. 
[...] o território deve ser apreendido como síntese contraditória, como totalidade concreta do processo/modo de produção/distribuição/circulação/ consumo e suas articulações e mediações supraestruturais (políticas, ideológicas, simbólicas etc.) em que o Estado desempenha a função de regulação. O território é assim produto concreto da luta de classes travada pela sociedade no processo de produção de sua existência (Oliveira, A., 1999, p. 74).

Com base no conceito acima exposto e na ideia de que o capital é, em essência, internacional, enquanto a lógica que envolve a terra é nacional, ele identifica as formações territoriais e as regiões como totalidades históricas constituídas por meio da espacialização contraditória do capital e suas articulações com a propriedade fundiária (Oliveira, A., 1999, p. 75). Assim, atreladas às duas situações determinadas pela expansão do capital monopolista acima discriminadas, o autor identifica as seguintes transformações territoriais observadas com a industrialização da agricultura ou introdução do modo industrial de produzir no campo:

(1) a territorialização do capital monopolista, que ocorre quando o capitalista da indústria, o proprietário de terra e o capitalista da agricultura são uma mesma pessoa ou empresa, como é frequente acontecer no setor sucroalcooleiro - nesses casos, predomina o estabelecimento da monocultura;

(2) a monopolização do território pelo capital, quando este não se territorializa como proprietário da terra, mas subordina a produção que é realizada nela ao seu controle via monopólio da circulação - situação que comporta a possibilidade de criação e reprodução camponesa e de formas de cultivo mais diversificadas (Oliveira, A., 1999, p. 105-106).

Nos anos 1990, quando cresce a organização dos trabalhadores rurais sem-terra e a luta pela reforma agrária, envolvendo espoliados diversos do processo de modernização e do avanço da especulação com a terra, multiplicam-se os estudos na geografia agrária uspiana sobre movimentos sociais, territorialização camponesa e experiências de assentamento rural existentes. É um momento importante de maior aproximação dos movimentos sociais e consolidação de uma geografia do campesinato, como se pode ver nos trabalhos de Valéria de Marcos (1996), Marta I. M. Marques (2000) e Larissa M. Bombardi (2001), hoje professoras da USP.

A questão agrária continua a ocupar lugar central no debate sobre o campo brasileiro, e outra vertente importante dos estudos da geografia agrária crítica uspiana são os trabalhos que buscam desvendar as irregularidades e os mecanismos de grilagem que marcam o avanço da propriedade fundiária. A participação de Ariovaldo U. de Oliveira na equipe responsável pela elaboração da proposta do II PNRA no primeiro governo Lula, em 2003, e seu acesso na ocasião aos dados do Incra sobre a totalidade das terras devolutas no país concorreu decisivamente para o desenvolvimento dessa vertente de pesquisa.

A temática da internacionalização da economia e seus reflexos na agricultura também tem recebido a atenção da geografia agrária crítica de longa data e vem merecendo maior destaque nos últimos anos. Em artigo da Geousp (Oliveira, A., 2015) e no livro A mundialização da agricultura brasileira (Oliveira, A., 2016c), o autor analisa a questão e afirma que, sob o capitalismo monopolista mundializado, a agricultura passou a se estruturar com base na tríade: produção de commodities, bolsas de mercadorias e de futuro e formação de empresas monopolistas mundiais. 
A participação de novos tipos de investidores capitalistas na produção agrícola e no mercado de terras, sobretudo representantes do capital financeiro, também tem sido objeto de pesquisas entre os autores da geografia agrária crítica como em Marques (2011) e em Pitta e Mendonça (2015). Vale ressaltar a contribuição de Oliveira a esse debate por meio do artigo "A questão da aquisição de terras por estrangeiros no Brasil - um retorno aos dossiês" publicado na revista Agrária em 2010, no qual o autor adverte para o risco de se supervalorizar o tema da estrangeirização das terras no país enquanto pouco se diz sobre manobras como o Programa Terra Legal do governo Lula que, assim como outras medidas adotadas em governos anteriores, ${ }^{5}$ premia a grilagem por meio do processo de regularização de terras.

\section{Considerações finais}

Os 40 anos de história da geografia crítica são um motivo de grande celebração na USP, um projeto que se concretizou e ganhou o mundo.

No caso específico da área de conhecimento aqui analisada, pode-se falar da consolidação de uma "nova geografia agrária" sob a liderança de Oliveira e de suas formulações teóricas hoje reconhecidas em todo o país e no exterior. Essa abordagem contribuiu muito para superar a perspectiva dualista - presa à oposição entre tradição e modernidade - em favor de uma compreensão do campo baseada na noção de desenvolvimento desigual e na apreensão da luta de classes como fator determinante do movimento da história.

Essa geografia continua a se ocupar da particularidade e diversidade do campo, mas não só. A perspectiva de totalidade adotada, tão cara para apreender o processo de mundialização em curso, permite identificar os processos e as determinações que unificam práticas, regiões e territórios sob o movimento desigual e contraditório de reprodução do modo capitalista de produção. A escola da geografia agrária uspiana se mantém fundamentada no materialismo dialético, dialogando com outras tradições e perspectivas teóricas e incorporando novos temas, a fim de acompanhar a dinâmica da realidade e novos desafios. Essa prática tem assegurado a vitalidade da geografia agrária crítica, garantindo sua sintonia com as transformações observadas no campo.

\section{Referências}

AGRÁRIA. Disponível em: http://www.revistas.usp.br/agraria/index. Acesso em: 27 nov. 2019.

ANDRADE, M. C. A terra e o homem no Nordeste. 4a ed. São Paulo: Ciências Humanas, 1980.

\section{BOMBARDI, L. M. O bairro, reforma agrária e o processo de territorialização}

camponesa. Dissertação (Mestrado em Geografia Humana) - Faculdade de Filosofia, Letras e Ciências Humanas, Universidade de São Paulo, São Paulo, 2001.

5 Fato que se repete em gestões posteriores, a exemplo da Lei n. 13.465/2017, do governo Temer, que amplia para 2.500 ha o limite da área de terra devoluta passível de regularização na Amazônia pelo Programa Terra Legal. 
CT. CAMPO-TERRITÓRIO: REVISTA DE GEOGRAFIA AGRÁRIA. Disponível em: http://www.seer.ufu.br/index.php/campoterritorio. Acesso em: 27 nov. 2019.

LEFEBVRE, H. Une pensée devenue monde. Paris: Fayard, 1980.

MARCOS, V. Comunidade sinsei (u)topia e territorialidade. Dissertação (Mestrado em Geografia Humana) - Faculdade de Filosofia, Letras e Ciências Humanas, Universidade de São Paulo, São Paulo, 1996.

MARQUES, M. I. M. O novo significado da questão agrária. In: ENANPEGE, 9., 2011. Goiânia. Anais... Goiânia: Anpege, 2011.

MARQUES, M. I. M. De sem terra a posseiro, a luta pela terra e a construção do território camponês no espaço da reforma agrária: o caso dos assentamentos nas fazendas Retiro e Velha-GO. Tese (Doutorado em Geografia Humana) - Faculdade de Filosofia, Letras e Ciências Humanas, Universidade de São Paulo, São Paulo, 2000.

MARTINS, J. S. Os camponeses e a política no Brasil. Petrópolis, RJ: Vozes, 1981.

MARX, K. O capital: crítica da economia política. 3a ed. São Paulo: Nova Cultural, 1988. v. 5. t. 2.

NERA. NÚCLEO DE ESTUDOS, PESQUISAS E PROJETOS DE REFORMA AGRÁRIA. Disponível em: http://revista.fct.unesp.br/index.php/nera. Acesso em: 27 nov. 2019 .

OLIVEIRA, A. U. A fronteira amazônica mato-grossense: grilagem, corrupção e violência. São Paulo: Iãnde, 2016a. Disponível em: http://agraria.fflch.usp.br/sites/agraria. fflch.usp.br/files/A\%20FRONTEIRA\%20AMAZ\%C3\%94NICA\%20MATO\%20 GROSSENSE.pdf. Acesso em: 15 jul. 2018.

OLIVEIRA, A. U. Crítica ao "estado isolado" de Von Thünen: contribuição para o estudo da geografia agrária. São Paulo: Iãnde, 2016b. Disponível em: http://agraria.fflch. usp.br/sites/agraria.fflch.usp.br/files/CR\%C3\%8DTICA\%20AO\%20ESTADO\%20 ISOLADO\%20DE\%20VON\%20THUNEN.pdf. Acesso em: 15 jul. 2018.

OLIVEIRA, A. U. A mundialização da agricultura brasileira. São Paulo: Iãnde, 2016c. Disponível em: http://agraria.fflch.usp.br/sites/agraria.fflch.usp.br/files/LIVRO\%20\%20 MUNDIALIZA\%C3\%87\%C3\%830\%20pronto.pdf. Acesso em: 15 jul. 2018.

OLIVEIRA, A. U. A mundialização do capital e a crise do neoliberalismo: o lugar mundial da agricultura brasileira. Geousp - Espaço e Tempo, São Paulo, v. 19, p. 228-244, 2015. Disponível: http://www.revistas.usp.br/geousp/article/view/102776. Acesso em: 21 jul. 2018.

OLIVEIRA, A. U. A questão da aquisição de terras por estrangeiros no Brasil: um retorno aos dossiês. Agrária, São Paulo, n. 12, p. 3-113, 27 jun. 2010. Disponível em: http://www. revistas.usp.br/agraria/article/view/702. Acesso em: 20 jul. 2018.

OLIVEIRA, A. U. A geografia agrária e as transformações territoriais recentes no campo brasileiro. In: CARLOS, A. F. A. (Org.). Novos caminhos da geografia. São Paulo: Contexto, 1999. p. 63-110. 
OLIVEIRA, F A economia brasileira: crítica à razão dualista. Petrópolis: Vozes, 1988.

OlIVEIRA, A. U. Agricultura e indústria no Brasil. Boletim Paulista de Geografia, São Paulo: AGB, n. 58, p. 5-64, 1981. Disponível em: http://www.agb.org.br/publicacoes/ index.php/boletim-paulista/article/view/1036/924. Acesso em: 18 maio 2018.

PALHETA, I. G. O uso da terra em Tauá-Vigia, estado do Pará. Tese (Doutorado em Geografia Humana) - Faculdade de Filosofia, Letras e Ciências Humanas, Universidade de São Paulo, São Paulo, 1978.

PITTA, F. T.; MENDONÇA, M. L. A empresa Radar S/A e a especulação com terras no Brasil. São Paulo: Outras Expressões, 2015. Disponível em: file://C:/Users/mimma/ Downloads/RevistaREDE2015paranet-2.pdf. Acesso em: 25 jul. 2018.

PORTO-GONÇALVES, C. W. A globalização da natureza e a natureza da globalização. Rio de Janeiro: Civilização Brasileira, 2006.

PORTO-GONÇALVES, C. W. A geografia está em crise. Viva a geografia! Boletim Paulista de Geografia, São Paulo: BPG, n. 55, p. 5-30, 1978. Disponível em: https://www. agb.org.br/publicacoes/index.php/boletim-paulista/article/view/1050/937. Acesso em: 13 jul. 2018.

PRADO JR., C. Formação do Brasil contemporâneo. 3a ed. São Paulo: Brasiliense, 1948.

QUIJANO, A. Colonialidade do poder e classificação social. In: SANTOS, B. S.; MENESES, M. P. (Org.). Epistemologias do sul. São Paulo: Cortez, 2010. p. 73-118.

SADER, M. R. C. T. Espaço e luta no Bico do Papagaio. Tese (Doutorado em Geografia Humana) - Faculdade de Filosofia, Letras e Ciências Humanas, Universidade de São Paulo, São Paulo, 1987.

SANTOS, M. Por uma geografia nova. 4a ed. São Paulo: Hucitec, 1996.

VALVERDE, O. Estudos de geografia agrária brasileira. Petrópolis: Vozes, 1984. 